\title{
Suplemento de baixo consumo para vacas de corte não-gestantes ${ }^{1}$
}

\section{Low intake supplement for non-pregnant beef cows}

\author{
Nelcino Francisco de Paula ${ }^{2 *}$; Mário Fonseca Paulino 3 ; Victor Rezende Moreira \\ Couto ${ }^{4}$; Edenio Detmann; ; Ivan França Smith Maciel5; Ériton Egídio Lisboa \\ Valente $^{6}$; Lívia Vieira de Barros ${ }^{7}$; Roberta Kely Viana Mendes ${ }^{5}$
}

\section{Resumo}

Este estudo foi realizado para avaliar o efeito do fornecimento de diferentes níveis de suplementos de baixo consumo sobre mudanças no peso e escore de condição corporal (ECC), consumo e digestibilidade dos nutrientes e eficiência de síntese de proteína microbiana de vacas com predominância de sangue Nelore (> 50\%), não gestante, com peso corporal inicial de 394,7 $\pm 13,14 \mathrm{~kg}$ em pastagem de Urochloa decumbens durante o período seco. Quatro tratamentos foram avaliados: Controle (somente mistura mineral), T250, T500 e T750, sendo 250, 500 e $750 \mathrm{~g}$ de suplemento/animal/dia, respectivamente. $\mathrm{O}$ experimento foi estruturado em delineamento inteiramente casualizado. Não houve efeito dos níveis de fornecimento de suplemento sobre o peso corporal final (PCF), ganho médio diário (GMD) e ECC final (ECCF), com médias de 409,8 kg, 0,181 kg e 4,85 pontos, respectivamente. Quanto ao consumo de nutrientes da dieta, observou-se que o consumo de proteína bruta (PB), carboidrato não-fibroso e extrato etéreo $(\mathrm{EE}) \mathrm{em} \mathrm{kg} /$ dia aumentaram à medida que aumentou-se os níveis de suplementação. $\mathrm{O}$ consumo de matéria seca (MS) médio foi $20,31 \mathrm{~g} / \mathrm{kg}$ de peso corporal. Notou-se efeito quadrático (da suplementação sobre os coeficientes de digestibilidade da MS, matéria orgânica, fibra em detergente neutro corrigida para cinza e proteína e nutrientes digestíveis totais. Efeito linear foi observado para os coeficientes de digestibilidade da PB e EE. O fornecimento de diferentes níveis de suplemento não influenciou a eficiência de síntese de proteína microbiana. Conclui-se que a suplementação em baixos níveis promove maior aporte de nutrientes, mas não é efetiva em promover mudanças no peso corporal de vacas não-gestantes.

Palavras-chave: Bovino de corte, digestibilidade, suplementação proteica, Urochloa decumbens

\footnotetext{
Abstract

The objective with this work was evaluate the effect of level different of low intake supplements on body weight (BW) change, body condition score (BCS), intake, digestibility and protein microbial efficiency of non-pregnancy cow, crossbreed, with Nellore blood predominance and initial BW of $394.7 \pm 13.14$ $\mathrm{kg}$ in Urochloa decumbens Stapf during dry season. Four treatments were evaluated: Control (without

1 Parte da Tese de Doutorado do primeiro autor

${ }^{2}$ Prof. Dr., Dept ${ }^{\circ}$ de Zootecnia e Extensão Rural, Faculdade de Agronomia, Medicina Veterinária e Zootecnia, Universidade Federal de Mato Grosso, UFMT, Cuiabá, MT. E-mail: nelcinodepaula@ufmt.br

${ }^{3}$ Profs. Drs., Dept ${ }^{\circ}$ de Zootecnia, Universidade Federal de Viçosa, UFV, Viçosa, MG. E-mail: mpaulino@ufv.br; detmann@ufv.br

${ }^{4}$ Prof. Dr. do Dept ${ }^{\circ}$ de Produção Animal, Universidade Federal de Goiás, UFG, Goiânia, GO. E-mail: victorzootecnista@hotmail.

${ }^{5}$ Discentes de Zootecnia, Universidade Federal de Viçosa, UFV, Viçosa, MG. E-mail: ivanfmaciel@yahoo.com.br; roberta.

${ }^{6}$ Prof. Dr., Dept ${ }^{\circ}$ de Zootecnia, Universidade Estadual do Oeste do Paraná, UNIOESTE, Toledo, PR. E-mail: eritonvalente@

7 Prof $^{\mathrm{a}}$ Dra $^{\mathrm{a}}$, Dept ${ }^{\mathrm{o}}$ de Agronomia, Universidade Estadual de Mato Grosso, Campus Cáceres, UNEMAT, Cáceres, MT. E-mail: barrosufv@yahoo.com.br
} com mendes@ufv.br yahoo.com.br

* Autor para correspondência 
supplementation), T250, T500, and T750, corresponding 250, 500, and $750 \mathrm{~g}$ of supplement/animal/ day, respectively. The experiment was carried in a completely randomized experimental design. There was not effect of the level supplementation on final BW, average gain daily (AGD), and BCS, with average of $409.8 \mathrm{~kg}, 0.181 \mathrm{~kg}$, and 4.85 point, respectively. There was increase $(\mathrm{P}<0.10)$ of the intake of crude protein (CP), non-fibrous carbohydrates, and ether extract (EE) with the level supplementation. The average total dry matter intake was $20.31 \mathrm{~g} / \mathrm{kg}$ of BW. The digestibility coefficients dry matter, organic matter, neutral detergent fiber, and total digestible nutrients showed a quadratic response and a linear effect $(\mathrm{P}<0.10)$ on digestibility coefficients of the $\mathrm{CP}$ and $\mathrm{EE}$ according supplementation level. The supplementation level not influenced $(\mathrm{P}>0.10)$ the microbial protein synthesis. Concluded that level supplementation increased the nutrient amount, but not able to increase the performance the animals.

Key words: Beef cattle, digestibility, protein supplementation, Urochloa decumbens

\section{Introdução}

A produção de bovinos de corte é claramente um importante elo do agronegócio brasileiro. $\mathrm{O}$ aumento global na demanda por produtos de origem animal tem gerado novas oportunidades para o setor, mas ao mesmo tempo, têm surgido novos desafios, especialmente quanto à necessidade de aumento na eficiência de produção de forma sustentável.

Os pastos representarem a base de alimentação da bovinocultura de corte desenvolvida em regiões tropicais, constituindo a principal fonte de nutrientes para os animais ao longo do ano. Todavia, em muitas situações o uso exclusivo destas gramíneas não tem permitido à maximização e/ou otimização da produção animal, dada as oscilações quali-quantitativa da forragem inerente ao clima tropical. Visualiza-se, portanto, a necessidade de suplementações com nutrientes limitantes em condições em que o suprimento de nutrientes não é condizente com o padrão de produção almejado (PAULINO; DETMANN; VALADARES FILHO, 2008).

Paralelamente a isto, os indicadores técnicos do ANUALPEC (2010) demonstram que o número de bezerros produzidos no Brasil em 2009 foi de aproximadamente 47 milhões de cabeças, com rebanho de vacas e novilhas (2 a 3 anos) de 72,4 milhões de cabeça. Logo, a taxa de natalidade fica em aproximadamente $65 \%$ e intervalo de partos de 18 meses. Estes dados são indicativos que o rebanho bovino brasileiro apresenta baixos índices reprodutivos.
Neste sentido, uma categoria animal que tem merecido atenção especial por parte dos produtores, são as vacas, haja visto que a manutenção e/ou melhoria no desempenho produtivo e reprodutivo destes animais é ferramenta fundamental para melhoria nos índices supracitados. Bellows e Short (1994) relataram que as maiores perdas no segmento de bovinocultura de corte de ciclo completo recaem sobre o fato de muitas vacas não estarem prenhes ao final da estação de monta.

É importante ressaltar, que em muitas situações, o não retorno a atividade reprodutiva, não pode ser visto como o momento para descarte de uma matriz, principalmente quando trata-se de primíparas, haja visto, que na maioria das vezes, este animal ainda não trouxe nenhum retorno financeiro do investimento em seu desenvolvimento, ou o sistema de produção não é tecnificado o suficiente para suportar tal descarte.

Neste aspecto, a nutrição tem sido considerada um dos fatores determinantes da duração do anestro pós-parto em bovinos de corte. Um dinâmico esquema de partição dos nutrientes determina que na alocação dos nutrientes para as várias funções do corpo, a atividade reprodutiva é tida como menos prioritária para o animal (SHORT et al., 1990).

Sendo assim, as vacas não prenhes ao final da estação de monta e que não forem descartadas devem adquirir e/ou manter condição corporal que permita o retorno a atividade reprodutiva no início da estação de monta seguinte. $\mathrm{O}$ uso de suplementos de baixo consumo pode ser uma ferramenta de 
manejo nutricional capaz de promover ganhos moderados e/ou manter a condição corporal destes animais a custos compatíveis. Poucos são os trabalhos avaliando o uso de suplementos em vacas não-prenhes, logo, faz-se necessária sua avaliação e maior entendimento.

Objetivou-se avaliar o uso de suplementos de baixo consumo sobre os parâmetros produtivos e nutricionais de vacas não-gestantes logo após o desmame dos bezerros.

\section{Material e Métodos}

O experimento foi conduzido no setor de Bovinocultura de Corte do Departamento de
Zootecnia da Universidade Federal de Viçosa, Viçosa - Minas Gerais - Brasil, entre os meses de agosto e outubro de 2009 (período seco), totalizando 84 dias.

Utilizaram-se 24 vacas mestiças, com predominância de sangue nelore ( $>50 \%$ ), nãogestantes, entre 5 e 6 anos de idade, distribuídas aleatoriamente em quatro tratamentos (suplementos de baixo consumo), a saber: T250 (250 g de suplemento/animal/dia), T500 (500 g de suplemento/ animal/dia) e T750 (750 g de suplemento/animal/ dia), e um tratamento em que os animais receberam apenas mistura mineral (Controle). Os suplementos foram formulados para conterem $400 \mathrm{~g}$ de $\mathrm{PB} /$ $\mathrm{kg}$ de suplemento (Tabela 1) e foram fornecidos diariamente por volta das 10:00h.

Tabela 1. Composição dos suplementos com base na matéria natural (MN).

\begin{tabular}{lc}
\hline Ingredientes & Proporção $(\mathrm{g} / \mathrm{kg}$ de $\mathrm{MN})$ \\
\hline Milho moído & 350 \\
Sorgo moído & 350 \\
Farelo de soja & 200 \\
Uréia: Sulfato de amônio $(9: 1)$ & 100 \\
\hline Mistura Mineral $(\mathrm{kg})^{1 / 2}$ & 0,100 \\
\hline
\end{tabular}

${ }^{1}$ Quantidade de mistura mineral adicionada ao suplemento/animal/dia;

${ }^{2}$ Composição percentual da mistura mineral: fosfato bicálcico, 50,00; cloreto de sódio, 47,775; sulfato de zinco,1,40; sulfato de cobre, 0,70; sulfato de cobalto, 0,05; iodato de potássio, 0,05 e selenito de sódio, 0,025 .

Fonte: Elaboração dos autores.

A área experimental constou-se de 4 piquetes de 5 ha cada, formado com Urochloa decumbens, providos de bebedouros e cochos. Os cochos tinham acesso bilateral, de forma a permitir acesso simultâneo de todos os animais. Controle de endo e ectoparasitas foram realizados no início do experimento e sempre que necessário.

No início e final do experimento os animais foram pesados, após jejum de aproximadamente 14 horas. O ganho de peso total (GPT) foi calculado pela diferença entre o peso corporal final (PCF) e o peso corporal inicial (PCI). Ao dividir o GPT pela duração do experimento, obteve-se o ganho médio diário (GMD). A cada 28 dias os animais foram pesados, bem como realizada a avaliação do escore de condição corporal (ECC) dos animais para monitoramento da variação de peso e condição corporal.

A cada 28 dias procedeu-se a amostragem da forragem disponível aos animais. Para avaliação quantitativa, a forragem foi cortada rente ao solo de quatro áreas delimitadas por um quadrado metálico de $0,5 \times 0,5 \mathrm{~m}\left(0,25 \mathrm{~m}^{2}\right)$ escolhidos aleatoriamente em cada piquete experimental. Após a coleta, as amostras foram pesadas e homogeneizadas, e a partir destas foram retiradas duas alíquotas: uma para avaliação da disponibilidade total de matéria seca (MS) e outra para análise da composição da 
massa disponível em termos de folha verde, folha seca, colmo verde e colmo seco. Das amostras destinadas à estimação da disponibilidade total de forragem, foi calculado o percentual de MS potencialmente digestível (MSpD) ofertada aos animais. Esse resultado foi obtido por intermédio do resíduo insolúvel em detergente neutro (FDNi) avaliado após incubação in situ (saco F57 Ankon) das amostras por 288 conforme recomendado por Valente et al. (2011). A MSpD foi calculada segundo a equação proposta por Paulino, Detmann e Valadares Filho (2008).

$$
M S p D=0,98 \times(100-F D N)+(F D N-F D N i)
$$

onde: $0,98=$ coeficiente de digestibilidade verdadeiro do conteúdo celular; FDN = fibra em detergente neutro; FDNi $=$ FDN indigestível.
Para avaliação qualitativa, amostras da forragem foram obtidas via simulação manual do pastejo animal a cada 28 dias.

A cada 7 dias os animais foram rotacionados nos piquetes, tendo em vista amenizar possíveis efeitos dos piquetes, especialmente quanto a disponibilidade e qualidade da forragem. Ressalta-se que os animais foram mantidos nos mesmos tratamentos.

As amostras para a avaliação quantitativa e qualitativa da forragem foram pesadas e imediatamente levadas para uma estufa com circulação forçada $\left(55^{\circ} \mathrm{C} / 72\right.$ horas $)$, processadas em moinho de facas tipo Wiley (1 e $2 \mathrm{~mm}$ ) e armazenadas para análise.

Os dados climáticos referentes ao período experimental foram coletados na estação meteorológica da Universidade Federal de Viçosa e estão apresentados na Figura 1.

Figura 1. Dados meteorológicos do período experimental.

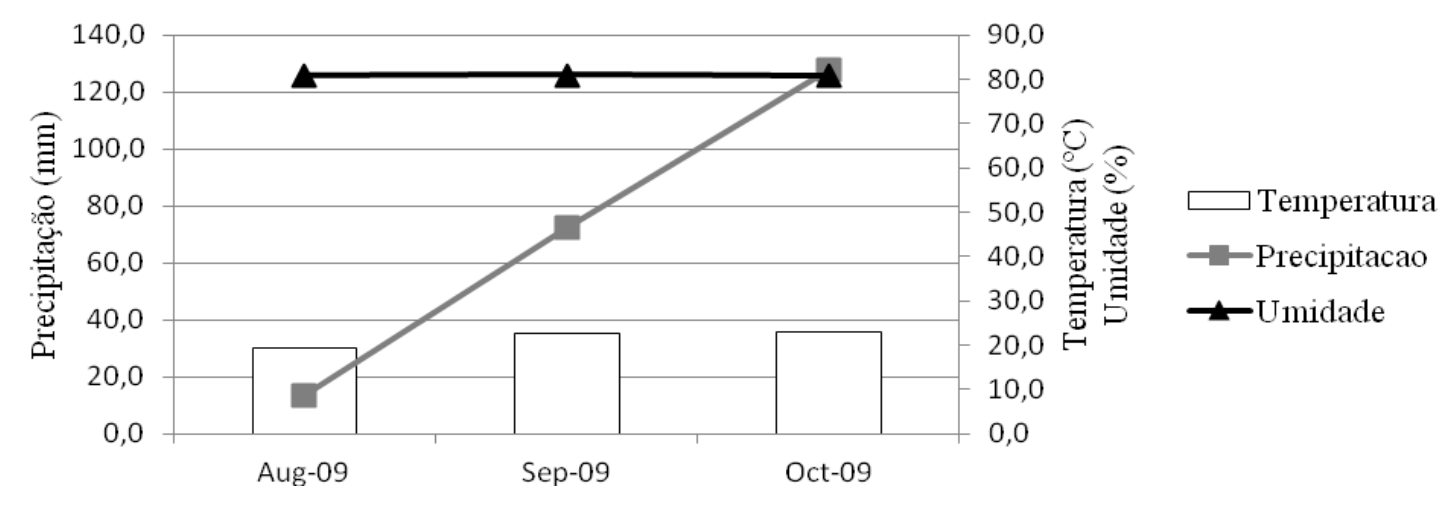

Fonte: Elaboração dos autores.

A avaliação das características nutricionais foi realizada na metade do período experimental por intermédio da técnica dos indicadores. Empregou-se o óxido crômico como indicador para estimativa da excreção fecal e o dióxido de titânio como indicador do consumo de suplemento (TITGEMEYER et al., 2001). A FDNi foi utilizada como indicador interno para estimativa do consumo de pasto.
O ensaio teve duração de nove dias, sendo os seis primeiros destinados à adaptação dos animais ao óxido crômico e dióxido de titânio e os três dias restantes para coletas em horários diferenciados. O dióxido de titânio foi adicionado diariamente ao suplemento concentrado de cada tratamento, na proporção de $15 \mathrm{~g} /$ animal/dia. O óxido crômico foi acondicionado em cartucho de papel (15 g) e aplicado via sonda esofágica. No $7^{\circ}, 8^{\circ}$ e $9^{\circ}$ dia do 
ensaio procedeu-se à coleta de amostras de fezes, tomadas diretamente no reto dos animais, às 16:00h, 12:00h e 08:00h, respectivamente. As amostras fecais foram identificadas e secas em estufa de ventilação forçada de ar. Posteriormente as amostras foram moídas em moinho de faca com peneira com malha de 1 e $2 \mathrm{~mm}$, sendo as amostras compostas por animal e armazenadas em potes plásticos.

No dia oito do ensaio procedeu-se uma avaliação quantitativa e qualitativa da forragem conforme descrito anteriormente.

No $9^{\circ}$ dia do ensaio foi realizada a coleta, nos animais, de amostras "spot" de urina, em micção espontânea e de sangue, realizadas aproximadamente quatro horas após o fornecimento do suplemento. Após a coleta, $10 \mathrm{~mL}$ de urina foram diluídas em $40 \mathrm{~mL}$ de $\mathrm{H}_{2} \mathrm{SO}_{4}$ 0,036 N conforme Valadares et al. (1999) e congeladas para posterior avaliação dos teores de creatinina, derivados de purina (ácido úrico e alantoína) e ureia.

As amostras de sangue foram coletadas após a coleta de urina utilizando-se tubos com vácuo e gel acelerador de coagulação (BD Vacuntainer ${ }^{\circledR}$ SST II Advance), sendo as amostras imediatamente centrifugadas e o plasma congelado para posterior determinação dos teores de ureia sérica.

Nas amostras de forragem obtidas via simulação manual, suplementos e fezes, processadas em peneiras de $1 \mathrm{~mm}$, foram avaliados os teores de MS, matéria orgânica (MO), PB, lignina (ácido sulfúrico $72 \% \mathrm{p} / \mathrm{p}$ ), extrato etéreo (EE), fibra em detergente neutro (FDN) e fibra em detergente ácido (FDA) com as devidas correções para cinza e proteína, constituindo-se a fibra em detergente neutro corrigida para cinza e proteína (FDNcp) e fibra em detergente ácido corrigida para cinza e proteína (FDAcp) de acordo com recomendações de Detmann et al. (2012). Os teores de carboidratos não fibrosos (CNF) seguiram recomendações de Detmann e Valadares Filho (2010);

$$
C N F=M O-[E E+F D N C P+(P B-P B u+U)
$$

em que: $\mathrm{CNF}=$ teor de carboidratos não-fibrosos $(\%) ; \mathrm{MO}=$ teor de matéria orgânica $(\%)$; $\mathrm{EE}=$ teor de extrato etéreo $(\%)$; FDNcp = teor de fibra em detergente neutro corrigida para cinzas e proteína $(\%) ; \mathrm{PB}=$ teor de proteína bruta $(\%) ; \mathrm{PBu}=$ teor de proteína bruta oriunda da ureia $(\%)$; $\mathrm{U}=$ teor de ureia (\%).

As amostras de fezes e óxido crômico foram analisadas quanto a concentração de cromo em espectrofotômetro de absorção atômica. Adicionalmente, as amostras de fezes e de dióxido de titânio foram analisadas por colorimetria quanto à concentração de titânio seguindo recomendações de Detmann et al. (2012).

As estimativas de consumo voluntário foram obtidas utilizando-se a FDNi como indicador interno, quantificadas por procedimento de incubação in situ por 288 horas, utilizando alíquotas processadas em peneira de malha $2 \mathrm{~mm}$, segundo recomendações de Valente et al. (2011).

A excreção de matéria seca fecal foi calculada como:

$$
M S F=\frac{Q F I}{C I F} \times 100
$$

em que: $\mathrm{MSF}=$ matéria seca fecal (g/dia); QFI $=$ quantidade fornecida do indicador $(\mathrm{g})$; CIF $=$ concentração do indicador (cromo) nas fezes (\%);

O consumo de matéria seca de suplemento $(\mathrm{kg} /$ dia) foi estimado segundo a equação:

$$
C S=\frac{M S F \times C I F}{C I S}
$$

em que: $\mathrm{CS}=$ consumo de matéria seca de suplemento $(\mathrm{kg} / \mathrm{dia}) ; \mathrm{MSF}=$ matéria seca fecal $(\mathrm{kg} / \mathrm{dia}) ; \mathrm{CIF}=$ concentração do indicador nas fezes $(\mathrm{kg} / \mathrm{kg})$; CIS = concentração do indicador no suplemento.

As estimativas do consumo voluntário foram obtidas segundo a equação: 


$$
C M S T=\frac{[(E F \times C I F)-(C S \times C I S)]}{C I F O}+C S
$$

em que: $\mathrm{CMST}=$ consumo de matéria seca total $(\mathrm{kg} / \mathrm{dia}) ; \mathrm{EF}=$ excreção fecal $(\mathrm{kg} / \mathrm{dia}) ; \mathrm{CIF}=$ concentração do indicador (FDNi) nas fezes $(\mathrm{kg} /$ $\mathrm{kg}) ; \mathrm{CS}=$ consumo de suplemento ( $\mathrm{kg} / \mathrm{dia})$; CIS = concentração do indicador (FDNi) no suplemento $(\mathrm{kg} / \mathrm{kg})$; e $\mathrm{CIFO}=$ concentração do indicador (FDNi) na forragem $(\mathrm{kg} / \mathrm{kg})$.

As amostras de urina e sangue foram analisadas quanto ao teores de ureia pelo método enzimáticocolorimétrico (Ureia Liquicolor - Human do Brasil - In Vitro Diagnóstica); assim como para ácido úrico na urina (Uric Acid Liquicolor - Human do Brasil - In Vitro Diagnóstica). Para análise de creatinina na urina utilizou-se o método do Picatro Alcalino (Creatinina - Human do Brasil - In Vitro Diagnóstica). As análises de alantoína foram realizadas pelo método colorimétrico, conforme método de Fujihara et al. (1987). O cálculo do volume urinário diário foi feito empregando-se a relação entre a excreção diária de creatinina (EC), proposta por Barbosa et al. (2006), e a sua concentração nas amostras spot:

$$
E C_{\left(\frac{m g}{k g} p V\right)}=27,11 \times P C
$$

Desta forma, a excreção urinária diária de compostos nitrogenados foi obtida pelo produto entre sua concentração nas amostras spot e o valor estimado de volume urinário.

A excreção total de derivados de purinas foi calculada pela soma das quantidades de alantoína e ácido úrico excretados na urina, expressas em $\mathrm{mmol} / \mathrm{dia}$.

As purinas absorvidas (Y, mmol/dia) foram calculadas a partir da excreção de derivados de purinas (X, mmol/dia), por intermédio da equação:

$$
Y=\frac{X-0,30 x P V^{0.75}}{0,80}
$$

em que: $0,80=$ recuperação de purinas absorvidas como derivados urinários de purinas; 0,30 x PV PV,75 $^{0}$ = contribuição endógena para a excreção de purinas (BARBOSA et al., 2011).

A síntese ruminal de compostos nitrogenados (Y, g Nmic/dia), calculada em função das purinas absorvidas (X, mmol/dia), utilizando-se a equação descrita por Chen e Gomes (1992), com exceção da relação $\mathrm{N}$ purinas: $\mathrm{N}$ total das bactérias de 0,137 , conforme Barbosa et al. (2011):

$$
Y=\frac{70 X}{0,93 \times 0,137 \times 1000}
$$

em que: 70 é o conteúdo de $\mathrm{N}$ de purinas ( $\mathrm{mgN} / \mathrm{mol})$; 0,137 , a relação $\mathrm{N}$ purinas: $\mathrm{N}$ total nas bactérias; e 0,93 , a digestibilidade das purinas bacterianas.

As variáveis estudadas foram analisadas segundo delineamento inteiramente casualizado. As comparações entre as médias observadas foram realizadas por meio da decomposição da soma de quadrados para tratamentos em contrastes ortogonais relativos aos efeitos de ordens linear, quadrática e cúbica em função da quantidade de suplemento. Quando os efeitos foram identificados, equações de regressão foram ajustadas. Todas as análises estatísticas foram realizados por intermédio do software SAS, adotando-se 0,10 como nível crítico de probabilidade para o erro tipo I.

\section{Resultados e Discussão}

As disponibilidades médias de MS e MSpD foram de 3408 e $2065 \mathrm{~kg} / \mathrm{ha}$ respectivamente. A disponibilidade de MSpD representou 60\% da disponibilidade de MS. Verificou-se baixa disponibilidade de folha verde, correspondendo a $14,3 \%$ da disponibilidade de MS. Adicionalmente, verificou-se elevada proporção $(73,8 \%)$ de colmo, notadamente colmo seco $(47,9 \%)$, o que pode ter dificultado o pastejo seletivo dos animais.

A forragem obtida via simulação manual do pastejo durante o período experimental apresentou 
teor médio de PB de 65,92 g/kg de MS (Tabela 2). Este valor está abaixo dos valores sugerido por Van Soest (1994) e Lazzarini et al. (2009) como mínimo para que não haja comprometimento do crescimento microbiano ruminal e, consequentemente, para que ocorra utilização eficiente dos carboidratos fibrosos da forragem basal.

Tabela 2. Composição química dos suplementos e da Urochloa decumbens com base na matéria seca $(\mathrm{kg} / \mathrm{kg})$.

\begin{tabular}{|c|c|c|}
\hline \multirow{2}{*}{ Item } & Suplemento & B.decumbens \\
\hline & \multicolumn{2}{|c|}{$(\mathrm{g} / \mathrm{kg}$ de $\mathrm{MS})$} \\
\hline Matéria seca & 909,4 & $414,21 \pm 4,025$ \\
\hline Matéria orgânica & 976,3 & $893,95 \pm 0,910$ \\
\hline Proteína bruta & 440,9 & $65,92 \pm 18,009$ \\
\hline Extrato etéreo & 21,6 & $5,21 \pm 0,562$ \\
\hline Fibra em detergente neutro ${ }^{2}(\mathrm{FDN})$ & 96,5 & $736,76 \pm 1,083$ \\
\hline Cinzas & 23,7 & $106,04 \pm 0,91$ \\
\hline Carboidratos não-fibrosos & 590,3 & $87,14 \pm 4,12$ \\
\hline Fibra em detergente ácido² & 31,3 & $391,76 \pm 4,19$ \\
\hline FDN indigestível & 10,8 & $295,98 \pm 73,07$ \\
\hline Lignina & 2,0 & $60,4 \pm 2,74$ \\
\hline
\end{tabular}

${ }^{2}$ corrigido para cinza e proteína.

Fonte: Elaboração dos autores.

Não foram verificados efeitos $(\mathrm{P}>0,10)$ da suplementação sobre o PCF, GMD e ECCF dos animais (Tabela 3). Verificou-se média de 409,8 kg, 0,181 kg e 4,85 pontos, para PCF, GMD e ECCF, respectivamente. Mesmo os animais que receberam apenas mistura mineral apresentaram acréscimo no PC, possivelmente isso seja resultado da ocorrência de chuvas no decorrer do período experimental
(Figura 1) e o surgimento de brotações de melhor qualidade. Vale ressaltar, o elevado coeficiente de variação para GMD, o que pode ter contribuído para a não identificação de diferenças significativas. Possivelmente este elevado coeficiente de variação esteja relacionado às diferenças no histórico nutricional dos animais deste experimento, conforme sugerido por Owens et al. (1995).

Tabela 3. Média de mínimos quadrados para desempenho de animais sob diferentes níveis de suplementação.

\begin{tabular}{|c|c|c|c|c|c|c|c|c|}
\hline \multirow{2}{*}{ Variáveis } & \multicolumn{4}{|c|}{ Suplementos (g/dia) } & \multirow{2}{*}{$\mathrm{CV}(\%)$} & \multicolumn{3}{|c|}{ Valor $\mathrm{P}^{1}$} \\
\hline & MM & $\mathrm{T} 250$ & T500 & $\mathrm{T} 750$ & & $\mathrm{~L}$ & $\mathrm{Q}$ & $\mathrm{C}$ \\
\hline $\mathrm{PCI}^{2}$ & 393,0 & 394,2 & 397,5 & 394,0 & - & - & - & - \\
\hline $\mathrm{PCF}^{3}$ & 405,0 & 407,2 & 411,7 & 415,5 & 15,32 & 0,757 & 0,977 & 0,979 \\
\hline $\mathrm{GMD}^{4}$ & 0,143 & 0,155 & 0,170 & 0,256 & 69,54 & 0,139 & 0,478 & 0,768 \\
\hline $\mathrm{ECCI}^{5}$ & 4,91 & 4,83 & 5,08 & 4,83 & - & - & - & - \\
\hline $\mathrm{ECCF}^{6}$ & 4,83 & 4,81 & 5,03 & 4,73 & 6,62 & 0,889 & 0,293 & 0,216 \\
\hline
\end{tabular}

${ }^{1} \mathrm{~L}, \mathrm{Q}$ e C: efeitos de ordem linear, quadrática e cúbica relativos à quantidade de suplemento fornecida. ${ }^{2} \mathrm{PCI}=$ peso corporal inicial. ${ }^{3} \mathrm{PCF}=$ peso corporal final. ${ }^{4} \mathrm{GMD}=$ ganho médio diário. ${ }^{5} \mathrm{ECCI}=$ escore de condição corporal inicial. ${ }^{6} \mathrm{ECCF}=$ escore de condição corporal final.

Fonte: Elaboração dos autores. 
Durante o período seco do ano, frequentemente tem sido observado perda de peso dos animais criados em regiões tropicais, em virtude de decréscimos na qualidade da forragem, notadamente digestibilidade e teores de PB (LAZZARINI et al., 2009). Sendo assim, a suplementação em baixos níveis, torna-se uma opção interessante, uma vez que geralmente tem baixo custo, e permite a manutenção da condição corporal e/ou moderado ganho de peso dos animais. Adicionalmente, estudos têm demonstrado que a nutrição tem sido considerada um dos fatores determinantes da duração do anestro pós-parto em bovinos de corte (SHORT et al., 1990). Embora não tenham sido notadas diferenças estatísticas no desempenho dos animais, o fornecimento de nutrientes, principalmente nitrogênio via suplementação, pode impactar sobremaneira o reinício da atividade reprodutiva de vacas que não emprenharam na estação de monta anterior por manter e/ou permitir ganhos moderados. Neste aspecto, mesmo que a magnitude da resposta seja moderada, o uso de suplementos de baixo consumo assume grande importância.

O ECC tem sido sugerido em detrimento ao peso corporal como possível ferramenta de avaliação do status nutricional de vacas. Dois animais podem ter marcada diferenças no peso corporal e similar escore de condição corporal. O ECCF médio observado neste estudo foi de 4,85. De acordo com o NRC (2000) para um animal com escore 5, correspondente aos animais do T500, passar para escore 6, seria necessário um ganho de aproximadamente $32 \mathrm{~kg}$ de peso corporal. No presente estudo, notou-se um aumento de apenas $14,2 \mathrm{~kg}$ no peso corporal para o tratamento T500.

Quanto ao consumo de nutrientes da dieta, observou-se que o consumo de PB (CPB), consumo de CNF (CCNF) e consumo de EE (CEE) em kg/dia aumentaram $(\mathrm{P}<0,10)$ a medida que aumentou-se os níveis de suplementação (Tabela 4). O consumo de MS total (CMST) médio foi $20,31 \mathrm{~g} / \mathrm{kg}$ de PC. Estes valores estão abaixo daqueles sugeridos pelo NRC (2000) de 23,8 g/kg de PC para vacas não-gestante com média de $400 \mathrm{~kg}$ de PC e GMD de $250 \mathrm{~g}$.

Frequentemente tem sido reportados acréscimos no CMST e consumo de MS de forragem (CMSF) com a suplementação proteica de forragens tropicais de baixa qualidade, notadamente quando a forragem apresenta teores de PB inferiores a $70 \mathrm{~g} /$ $\mathrm{kg}$ de MS (DELCURTO et al., 1990; SAMPAIO et al., 2010; LAZZARINI et al., 2009). Este aumento pode ser reflexo do aumento na digestibilidade de componentes fibrosos que promovem alto efeito de enchimento no ambiente ruminal (DELCURTO etal., 1990; LAZZARINI et al., 2009). Segundo Detmann et al. (2003) o efeito de enchimento é esperado para ser o principal mecanismo controlador do consumo de animais alimentados com forragem de baixa qualidade. Ademais, Mertens (1994) sugeriu que o consumo de MS é maximizado quando o consumo de FDN é aproximadamente $12,5 \mathrm{~g} / \mathrm{kg}$ de PC, sendo frequentemente observado com gramíneas C4 (BOHNERT et al., 2011). Os dados do presente estudo parecem estar de acordo com as hipóteses supracitadas. Em nosso estudo, o consumo médio de FDNcp foi de aproximadamente $14,4 \mathrm{~g} / \mathrm{kg}$ de $\mathrm{PC}$, sendo portanto superior aos valores sugeridos por Mertens (1994).

Ademais, entende-se que o consumo de MS não deve estar relacionado somente às características químicas da forragem, mas também a proporção dos componentes da forragem (folha verde, folha seca, colmo verde e colmo seco) que determinam o grau de seletividade dos animais. Portanto, a presença de maiores proporções de colmo conforme mencionado anteriormente pode ter promovido efeito deletério sobre o consumo, em virtude da maior dificuldade na seletividade e apreensão da forragem. 
Tabela 4. Média de mínimos quadrados e coeficiente de variação para o consumo dos componentes da dieta.

\begin{tabular}{|c|c|c|c|c|c|c|c|c|}
\hline \multirow{2}{*}{ Variável } & \multicolumn{4}{|c|}{ Suplementos (kg/dia) } & \multirow{2}{*}{$\mathrm{CV}(\%)$} & \multicolumn{3}{|c|}{ Valor $\mathrm{P}^{1}$} \\
\hline & MM & $\mathrm{T} 250$ & T500 & $\mathrm{T} 750$ & & $\mathrm{~L}$ & $\mathrm{Q}$ & $\mathrm{C}$ \\
\hline \multicolumn{9}{|c|}{$\mathrm{kg} / \mathrm{dia}$} \\
\hline MST & 8,642 & 8,529 & 8,672 & 8,835 & 15,57 & 0,773 & 0,805 & 0,924 \\
\hline MSP & 8,642 & 8,202 & 8,118 & 8,053 & 15,64 & 0,441 & 0,725 & 0,888 \\
\hline MSS & 0,080 & 0,327 & 0,555 & 0,782 & - & - & - & - \\
\hline MO & 7,718 & 7,646 & 7,793 & 7,958 & 15,60 & 0,700 & 0,814 & 0,929 \\
\hline MOP & 7,718 & 7,324 & 7,249 & 7,192 & 15,64 & 0,441 & 0,725 & 0,888 \\
\hline FDNcp & 6,377 & 6,074 & 6,033 & 6,008 & 15,60 & 0,518 & 0,725 & 0,888 \\
\hline FDNi & 1,911 & 1,816 & 1,800 & 1,788 & 15,63 & 0,469 & 0,725 & 0,888 \\
\hline $\mathrm{PB}^{1}$ & 0,500 & 0,576 & 0,672 & 0,770 & 22,98 & 0,003 & 0,856 & 0,942 \\
\hline $\mathrm{CNF}^{2}$ & 0,800 & 0,994 & 1,120 & 1,248 & 23,14 & 0,003 & 0,744 & 0,877 \\
\hline $\mathrm{EE}^{3}$ & 0,040 & 0,043 & 0,048 & 0,052 & 18,85 & 0,018 & 0,806 & 0,922 \\
\hline NDT & 4,633 & 4,912 & 4,919 & 4,949 & 16,66 & 0,524 & 0,711 & 0,843 \\
\hline \multicolumn{9}{|c|}{$\mathrm{g} / \mathrm{kg} \mathrm{PC}$} \\
\hline MS & 20,535 & 20,040 & 20,267 & 20,402 & 9,47 & 0,962 & 0,692 & 0,819 \\
\hline MSP & 20,535 & 19,276 & 18,980 & 18,670 & 10,82 & 0,139 & 0,586 & 0,800 \\
\hline MO & 18,339 & 17,965 & 18,212 & 18,370 & 9,38 & 0,914 & 0,708 & 0,823 \\
\hline MOP & 18,339 & 17,214 & 16,950 & 16,672 & 10,82 & 0,139 & 0,586 & 0,800 \\
\hline FDNcp & 15,151 & 14,274 & 14,106 & 13,921 & 10,63 & 0,181 & 0,585 & 0,796 \\
\hline FDNi & 4,542 & 4,270 & 4,209 & 4,145 & 10,74 & 0,153 & 0,585 & 0,799 \\
\hline
\end{tabular}

${ }^{1 /} \hat{Y}=0,494+0,00036 \mathrm{X}\left(\mathrm{r}^{2}=0,997\right) ;{ }^{2 /} \hat{\mathrm{Y}}=0,820+0,0006 \mathrm{X}\left(\mathrm{r}^{2}=0,988\right) ;{ }^{3 /} \hat{\mathrm{Y}}=0,0397+0,00002 \mathrm{X}\left(\mathrm{r}^{2}=0,9893\right) . \mathrm{L}, \mathrm{Q}$ e $\mathrm{C}=$ efeito de odem linear, quadrática e cúbica, respectivamente. MST = matéria seca total; MSP = matéria seca de pasto; MSS = matéria seca de suplemento; $\mathrm{MO}$ = matéria orgânica; $\mathrm{MOP}$ = matéria orgânica de pasto; FDNcp = FDN corrigida para cinza e proteína; $\mathrm{FDNi}$ = fibra em detergente neutro indigestível; $\mathrm{PB}=$ proteína bruta; $\mathrm{CNF}$ = carboidrato não fibroso; $\mathrm{EE}=$ extrato etéreo; $\mathrm{NDT}=$ Nutrientes digestíveis totais.

Fonte: Elaboração dos autores.

Adicionalmente, Moore et al. (1999) em revisão sobre os efeitos da suplementação sobre o consumo de forragem, sugeriram que quando o consumo de $\mathrm{MO}(\mathrm{CMO})$ for superior a $17,5 \mathrm{~g} / \mathrm{kg}$ de $\mathrm{PC}$, acréscimos no consumo não são esperados com a suplementação. Em nosso estudo, não foram notadas diferenças no $\mathrm{CMO}$, sendo o consumo para os animais que receberam apenas mistura mineral de $18,339 \mathrm{~g} / \mathrm{kg}$ de $\mathrm{PC}$ e portanto superior ao valor supracitado. O CMO médio do presente estudo foi de aproximadamente $18 \mathrm{~g} / \mathrm{kg}$ de PC.
$\mathrm{O}$ efeito crescente observado sobre o $\mathrm{CPB}$, CCNF e CEE à medida que se aumenta os níveis de suplementação pode ser devido às maiores concentrações destes nutrientes no suplemento em relação à forragem e a ausência de diferenças no CMST.

Notou-se efeito quadrático $(\mathrm{P}<0,10) \quad$ da suplementação sobre o coeficiente de digestibilidade da MS, MO, FDNcp e NDT (Tabela 5). Efeito linear $(\mathrm{P}<0,10)$ foi observado para os coeficientes de digestibilidade da PB e EE. O comportamento quadrático observado indica que houve decréscimo no coeficiente de digestibilidade a partir do nível $500 \mathrm{~g}$ de suplemento. 
Tabela 5. Coeficiente de digestibilidade total ( $\mathrm{g} / \mathrm{kg}$ de MS) e teores de nutrientes digestíveis total das dietas.

\begin{tabular}{|c|c|c|c|c|c|c|c|c|}
\hline \multirow{2}{*}{ Variável } & \multicolumn{4}{|c|}{ Suplementos (g/dia) } & \multirow{2}{*}{$\mathrm{CV}(\%)$} & \multicolumn{3}{|c|}{ Valor $-P$} \\
\hline & MM & $\mathrm{T} 250$ & T500 & $\mathrm{T} 750$ & & $\mathrm{~L}$ & $\mathrm{Q}$ & $\mathrm{C}$ \\
\hline \multicolumn{9}{|c|}{$\%$} \\
\hline $\mathrm{MS}^{1}$ & 57,55 & 61,34 & 59,92 & 57,81 & 2,53 & 0,811 & $<0.0001$ & 0,1005 \\
\hline $\mathrm{MO}^{2}$ & 59,66 & 62,90 & 61,84 & 59,39 & 1,78 & 0,347 & $<0.0001$ & 0,1452 \\
\hline $\mathrm{PB}^{3}$ & 40,60 & 49,60 & 52,71 & 54,57 & 13,09 & 0,001 & 0,191 & 0,699 \\
\hline $\mathrm{EE}^{4}$ & 47,31 & 50,35 & 53,19 & 54,93 & 3,79 & $<0,0001$ & 0,4259 & 0,8045 \\
\hline FDNcp 5 & 69,13 & 70,95 & 69,94 & 68,98 & 1,38 & 0,3985 & 0,0015 & 0,1017 \\
\hline $\mathrm{NDT}^{6}$ & 53,50 & 57,59 & 56,67 & 55,92 & 3,17 & 0,0641 & 0,0033 & 0,1248 \\
\hline
\end{tabular}

${ }^{1 /} \hat{\mathrm{Y}}=0,5778+0,0002 \mathrm{X}-0,00000023 \mathrm{X}^{2} ;{ }^{2 /} \hat{\mathrm{Y}}=0,5981+0,00016 \mathrm{X}-0,00000023 \mathrm{X}^{2} ;{ }^{3 /} \hat{\mathrm{Y}}=0,426+0,0002 \mathrm{X} ;{ }^{4 /} \hat{\mathrm{Y}}=0,476+$ $0,0001 \mathrm{X} ;{ }^{5 /} \hat{\mathrm{Y}}=0,6927+0,000077 \mathrm{X}-0,0000001 \mathrm{X}^{2} ;{ }^{6 /} \hat{\mathrm{Y}}=0,538+0,0002 \mathrm{X}-0,0000002 \mathrm{X}^{2}$. L, Q e C $=$ efeito de odem linear, quadrática e cúbica, respectivamente. $\mathrm{MS}=$ matéria seca; $\mathrm{MO}=$ matéria orgânica; $\mathrm{PB}$ = proteína bruta; $\mathrm{EE}=$ extrato etéreo; $\mathrm{FDNcp}$ $=$ FDN corrigida para cinza e proteína e NDT $=$ Nutrientes digestíveis totais.

Fonte: Elaboração dos autores.

A baixa digestibilidade da PB dos animais que receberam apenas mistura mineral em relação àqueles que receberam suplementação pode ser resultado dos elevados teores de fibra e baixo teor de proteína na forragem utilizada no presente estudo (Tabela 2). Tal fato pode resultar em significante proporção de nitrogênio nas fezes (BOHNERT; SCHAUER; DELCURTO, 2002).

Quanto ao metabolismo do nitrogênio (Tabela 6), não se observou efeito $(\mathrm{P}>0,10)$ da suplementação sobre o nitrogênio urinário (NU). A despeito da ausência de diferenças para NU, observou-se elevado coeficiente de variação, o que possivelmente não permitiu a identificação de diferenças. Por outro lado, notou-se que os níveis séricos de nitrogênio (NUS) aumentaram $(\mathrm{P}<0,10)$ com aumento nos níveis de suplementação. Quanto ao fluxo de nitrogênio microbiano (NMIC) não foi notado efeito da suplementação. No tocante a eficiência de uso do nitrogênio, também não foi notada diferenças $(\mathrm{P}>0,10)$ para Pbmic (g/kg de NDT).

Para NUS houve acréscimo de 48,7, 61,4 e $84,4 \%$ para T250, T500 e T750 g, respectivamente em relação ao suplemento controle. Vale ressaltar, que o suplemento do presente estudo continha $10 \%$ de uréia que é mais rapidamente solubilizada no ambiente ruminal e convertida a amônia que fontes de proteína verdadeira. Quando os teores de amônia estão em excesso e/ou não são utilizado pelas bactérias ruminais por deficiência de esqueletos de carbono, a amônia atravessa a parede do rúmen e entra na corrente sanguínea. No fígado a amônia é convertida em ureia que pode retornar ao rúmen por difusão e/ou via saliva, ou ser excretada através da urina.

Portanto, a concentração de NUS comporta-se de forma similar ao consumo de nitrogênio e/ou PB, suportando a hipótese que a concentração de nitrogênio no soro ou plasma é positivamente correlacionada com o CPB (HARMEYER; MARTENS, 1980; BOHNERT et al., 2011). Adicionalmente, Harmeyer e Mertens (1980) sugerem que a proporção de NUS que retorna ao trato gastrointestinal pode variar de 10 a $95 \%$ e é negativamente correlacionado com o consumo de nitrogênio.

A ausência de diferenças na eficiência de síntese de proteína microbiana possivelmente seja resultado dos elevados níveis de FDN da forragem, que podem dificultar a disponibilidade de esqueleto de carbono para utilização de nitrogênio advindo de fontes rapidamente solúveis, como é o caso do suplemento do presente estudo com $10 \%$ de uréia na composição. Sendo assim, provavelmente a taxa na qual a energia é disponibilizada seja o fator mais limitante à síntese de proteína microbiana, uma vez que carboidratos fibrosos apresentam lenta taxa de digestão. 
Tabela 6. Média de mínimos quadrados e coeficiente de variação para os parâmetros de utilização do nitrogênio.

\begin{tabular}{lcccccccc}
\hline \multirow{2}{*}{ Variável } & \multicolumn{3}{c}{ Suplementos (g/dia) } & \multirow{2}{*}{ CV $(\%)$} & \multicolumn{3}{c}{ Valor $-P$} \\
\cline { 2 - 4 } \cline { 7 - 9 } & MM & T250 & T500 & T750 & & L & C \\
\hline Nmic (g/dia) & 85,7 & 86,1 & 84,4 & 83,5 & 44,9 & 0,2023 & 0,6284 & 0,8909 \\
NU (mg/dL) & 73,1 & 90,9 & 84,6 & 102,2 & 81,3 & 0,5415 & 0,9973 & 0,7158 \\
NUS $^{1}$ (g/dL) & 10,0 & 14,9 & 16,2 & 18,5 & 13,5 & $<0,0001$ & 0,1327 & 0,2204 \\
\hline \multicolumn{9}{c}{ Eficiência Microbiana } \\
\hline Pbmic (g/kg NDT) & 120,2 & 110,6 & 112,2 & 118,1 & 49,4 & 0,9647 & 0,7416 & 0,9463 \\
\hline
\end{tabular}

${ }^{1 /} \hat{Y}=10,917+0,011 X ; L, Q$ e C $=$ efeito de odem linear, quadrática e cúbica, respectivamente. Nmic = nitrogênio microbiano; $\mathrm{NU}$ = nitrogênio urinário; NUS = nitrogênio ureico no soro; Pbmic = proteína bruta microbiana; Nmic/Ning = relação Nitrogênio microbiano: nitrogênio ingerido.

Fonte: Elaboração dos autores.

Souza et al. (2010) relataram que a suplementação exclusiva com compostos nitrogenados embora possa aumentar o consumo e utilização de FDN no rúmen, pode não aumentar a assimilação de nitrogênio pelos microrganismos ruminais, possivelmente isto seja resultado do ineficiente acoplamento da energia da FDN. Por outro lado a suplementação com nitrogênio e amido promove alta assimilação de nitrogênio no rúmen.

\section{Conclusão}

A suplementação até 750 g/animal/dia proporciona maior aporte de nutrientes aos animais, mas não promove mudanças no peso e escore de condição corporal de vacas de corte não-gestantes.

\section{Agradecimentos}

À Fundação de Amparo à Pesquisa do Estado de Minas Gerais (FAPEMIG) pelo financiamento para realização deste trabalho de pesquisa.

\section{Referências}

ANUÁRIO DA PECUÁRIA BRASILEIRA ANUALPEC. São Paulo: FNP Consultoria e Comércio, 2010. 360 p.

BARBOSA, A. M.; VALADARES, R. F. D.; VALADARES FILHO, S. C.; PINA, D. S.; DETMANN, E.; LEÃO, M. I. Endogenous fraction and urinary recovery of purine derivatives obtained by different methods in Nellore cattle. Journal of Animal Science, Champaign, v. 89, n. 2, p. 510-519, 2011.

BARBOSA, A. M.; VALADARES, R. F. D.; VALADARES FILHO, S. C.; VÉRAS, R. M. L.; LEÃO, M. I.; DETMANN, E.; PAULINO, M. F.; MARCONDES, M. I.; SOUZA, M. A. Effect of urinary collection days, concentrate levels and protein sources on creatinine, urea and purine derivatives excretions and microbial protein synthesis in Nellore cattle. Revista Brasileira de Zootecnia, Viçosa, MG, v. 35, n. 3, p. 870-877, 2006.

BELLOWS, R. A.; SHORT, R. E. Reproductive losses in the beef industry. In: FIELDS, M. J.; SANDS, R. S. (Ed.). Factors affecting calf crop. Baton Rouge: CRC Press, 1994. p. 109-133.

BOHNERT, D. W.; DELCURTO, T.; CLARK, A. A.; MERRILL, M. L; FALCK, S. J.; HARMON, D. L. Protein supplementation of ruminants consuming low-quality cool- or warm-season forage: Differences in intake and digestibility. Journal of Animal Science, Champaign, v. 89, n. 11, p. 3707-3717, 2011.

BOHNERT, D. W.; SCHAUER, C. S.; DELCURTO, $\mathrm{T}$. Influence of rumen protein degradability and supplementation frequency on performance and nitrogen use in ruminants consuming low-quality forage: Cow performance and efficiency of nitrogen use in wethers. Journal of Animal Science, Champaign, v. 80, n. 6, p. 1629-1637, 2002.

CHEN, X. B.; GOMES, M. J. Estimation of microbial protein supply to sheep and cattle based on urinary excretion of purine derivatives - an overview of technical details. Aberdeen: International Feed Research Unit. Rowett Research Institute, Occasional Publication, 1992. $21 \mathrm{p}$.

DELCURTO, T.; COCHRAN, R. C.; HARMON, D. L.; BEHARKA, A. A.; JACQUES, K. A.; TOWNE, G.; VANZANT, E. S. Supplementation of dormant tallgrass- 
prairie forage: I. Influence of varying supplemental protein and(or) energy levels on forage utilization characteristics of beef steers in confinement. Journal of Animal Science, Champaign, v. 68, n. 2, p. 515-531, 1990.

DETMANN, E.; QUEIROZ, A. C.; CECON, P. R.; ZERVOUDAKIS, J. T.; PAULINO, M. F.; VALADARES FILHO, S. C.; CABRAL, L. S.; LANA, R. P. Neutral detergent fiber intake by feedlot cattle. Revista Brasileira de Zootecnia, Viçosa, MG, v. 32, n. 6S, p. 1763-1777, 2003.

DETMANN, E.; SOUZA, M. A.; VALADARES FILHO, S. C.; QUEIROZ, A. C.; BERCHIELLI, T. T.; SALIBA, E. O. S.; CABRAL, L. S.; PINA, D. S.; LADEIRA, M. M.; AZEVEDO, J. A. G. (Ed.). Métodos para análise de alimentos. Visconde do Rio Branco: INCT-Ciência Animal, 2012. $214 \mathrm{p}$.

DETMANN, E.; VALADARES FILHO, S. C. On the estimation of non-fibrous carbohydrates in feeds and diets. Arquivo Brasileiro de Medicina Veterinária e Zootecnia, Belo Horizonte, v. 62, n. 4, p. 980-984, 2010.

FUJIHARA, T.; ORSKOV, E. R.; REEDS, P. J.; KYLE, D. J. The effect of protein infusion on urinary excretion of purine derivatives in ruminants nourished by intragastric nutrition. The Journal of Agricultural Science, Cambridge, v. 109, n. 1, p. 7-12, 1987.

HARMEYER, J.; MARTENS, H. Aspects of urea metabolism in ruminants with reference to the goat. Journal Dairy Science, Madison, v. 63, n. 10, p. 17071728, 1980.

LAZZARINI, I.; DETMANN, E.; SAMPAIO, C. B.; PAULINO, M. F.; VALADARES FILHO, S. C.; SOUZA, M. A.; OLIVEIRA, F. A. Intake and digestibility in cattle fed low-quality tropical forage and supplemented with nitrogenous compounds. Revista Brasileira de Zootecnia, Viçosa, MG, v. 38, n. 10, p. 2021-2030, 2009.

MERTENS, D. R. Regulation of forage intake. In: FAHEY JUNIOR, G. C.; COLLINS, M.; MERTENS, D. R. (Ed.). Forage quality evaluation and utilization. Nebraska: American Society of Agronomy, Crop Science of America; Soil Science of America, 1994. 988 p.

MOORE, J. E.; BRANT, M. H.; KUNKLE, W. E.; HOPKINS, D. I. Effects of supplementation on voluntary forage intake, diet digestibility, and animal performance. Journal of Animal Science, Champaign, v. 77, p. 122135, 1999. Supplement 2.

NATIONAL RESEARCH COUNCIL - NRC. Nutrient requirements of beef cattle. 7. ed. Washington: D.C.: National Academy Press, 2000. 243 p.
OWENS, F. N.; GILL, D. R.; SECRIST, D. S.; COLEMAN, S. W. Review of some aspects of growth and development of feedlot cattle. Journal of Animal Science, Champaign, v. 73, n. 10, p. 3152-3172, 1995.

PAULINO, M. F.; DETMANN, E.; VALADARES FILHO, S. C. Bovinocultura funcional nos tópicos. In: SIMPÓSIO DE PRODUÇÃO DE GADO DE CORTE, 6.; SIMPÓSIO INTERNACIONAL DE PRODUÇÃO DE GADO DE CORTE, 2., 2008, Viçosa. Anais... Viçosa: VI SIMCORTE, 2008. p. 275-305.

SAMPAIO, C. B.; DETMANN, E.; PAULINO, M. F.; VALADARES FILHO, S. C.; SOUZA, M. A.; LAZZARINI, I.; PAULINO, P. V. R.; QUEIROZ, A. C. Intake and digestibility in cattle fed low-quality tropical forage and supplemented with nitrogenous compounds. Tropical Animal Health and Production, London, v. 42, n. 7, p. 1471-1479, 2010.

SHORT, R. E.; BELLOWS, R. A.; STAIGMILLER, R. B.; BERARDINELLI, J. G.; CUSTER, E. E. Physiological mechanisms controlling anestrus and infertility in postpartum beef cattle. Journal of Animal Science, Champaign, v. 68, n. 3, p. 799-816, 1990.

SOUZA, M. A.; DETMANN, E.; PAULINO, M. F.; SAMPAIO, C. B.; LAZZARINI, I.; VALADARES FILHO, S. C. Intake, digestibility and rumen dynamics of neutral detergent fibre in cattle fed low-quality tropical forage and supplemented with nitrogen and/or starch. Tropical Animal Health and Production, London, v. 42, n. 6, p. 1299-1310, 2010.

TITGEMEYER; E. C.; ARMENDARIZ, C. K.; BINDEL, D. J.; GREENWOOD, R. H.; LOEST, C. A. Evaluation of titanium dioxide as a digestibility marker for cattle. Journal of Animal Science, Champaign, v. 79, n. 4, p. 1059-1063, 2001.

VALADARES, R. F. D.; BRODERICK, G. A.; VALADARES FILHO, S. C.; CLAYTON, M. K. Effect of replacing alfalfa silage with high moisture corn on ruminal protein synthesis estimated from excretion of total purine derivatives. Journal of Dairy Science, Madison, v. 82, n. 11, p. 2686-2696, 1999.

VALENTE, T. N. P.; DETMANN, E.; QUEIROZ, A. C.; VALADARES FILHO, S. C.; GOMES, D. I.; FIGUEIRAS, J. F. Evaluation of ruminal degradation profiles of forages using bags made from different textiles. Revista Brasileira de Zootecnia, Viçosa, MG, v. 40, n. 11, p. 2565-2573, 2011.

VAN SOEST, P. J. Nutritional ecology of the ruminant. 2. ed. Ithaca: Cornell University, 1994. 476 p. 